\title{
Comparison efficacy of randomized nebulized magnesium sulfate and ipratropium bromide/fenoterol in children with moderate to severe asthma exacerbation
}

\author{
Siriporn Wongwaree, ${ }^{1}$ Tassalapa Daengsuwan ${ }^{1}$
}

\begin{abstract}
Background: In Thailand, nebulized ipratropium bromide/fenoterol, is commonly used in addition to salbutamol for severe asthma exacerbation. Recently, nebulized $\mathrm{MgSO}_{4}$ is indicated in GINA 2015 as an additive treatment for severe cases. However, there is limited data showed the efficacy of both drugs in childhood severe asthma. The purpose of this study to compare efficacy and safety of nebulized $\mathrm{MgSO}_{4}$ and ipratropium bromide/fenoterol in moderate to severe asthma attacks.
\end{abstract}

Methods: In this a prospective, double-blind, randomized, controlled trial study, we enrolled thirty-three children, age ranged from 2 to 15 years old, with PRAM score $\geq 4$ (moderate to severe asthma exacerbation) despite 3 doses of nebulized salbutamol. Each patient was randomized to receive either three doses of nebulized $\mathrm{MgSO}_{4}$ or nebulized ipratropium bromide/fenoterol every 30 minutes. The PRAM score was measured at 0, 30, 60, 90, 120 and 240 minutes after the treatment. The adverse event and admission days were also evaluated.

Results: Sixteen patients received nebulized $\mathrm{MgSO}_{4}$ and seventeen received nebulized ipratropium bromide/fenoterol. Almost patients were classified as having moderate asthmatic attack. There were no statistically significant difference between the two study groups in almost baseline characteristic, PRAM score at 0, 30, 60, 90, 120, 240 minutes. The hospital length of stay was also similar between two groups $(\mathrm{p}=0.83)$. There were no serious events in both groups.

Conclusions: Our double blind, randomized, controlled pilot study demonstrated non-inferior outcomes including clinical benefit and safety of nebulized $\mathrm{MgSO}_{4}$ and nebulized ipratropium bromide/fenoterol among Thai children with acute moderate asthmatic attack.

Key words: asthma, acute asthmatic attack, severe acute asthma, nebulized magnesium sulfate, nebulized ipratropium bromide/fenoterol, isotonic magnesium sulfate

From:

Division of Allergy and Immunology, Department of Pediatrics, Queen Sirikit National Institute of Child Health, Bangkok, Thailand

\section{Corresponding author:}

Tassalapa Daengsuwan

Division of Pediatrics Allergy and Immunology,

Department of Pediatrics, Queen Sirikit National Institute of Child Health, Bangkok, Thailand 10400

E-mail: Tassalapa@gmail.com

\section{Introduction}

Among chronic respiratory illness of childhood, asthma is the most common life-threatening disease. When exposing to triggers, the lower airway could abruptly constrict and inflame. Inhaled salbutamol, the well-known bronchodilator is usually used as the first line therapy to relieve bronchospasm. However, patients with severe asthmatic attack who do not respond well to this initial treatment, the addition medication such as nebulized ipratropium bromide is recommended by the international standard guideline and nebulized $\mathrm{MgSO}_{4}$ is indicated as additive treatment. ${ }^{1,2}$ Ipratropium bromide, one of anticholinergic which approved to treat acute asthma, is an antagonist for muscarinic receptor. Although this medication does not work well when used alone to treat asthmatic attack but it shows significant reduction in hospital admissions both children and adults when applied multiple doses in combination with beta ${ }_{2}$ agonist. $^{3,4}$ In Thailand, the cheap combination of ipratropium bromide and fenoterol, the short acting beta ${ }_{2}$ agonist, is widely added after failed treatment with multiple doses 
of salbutamol. However, the efficacy of this combination was not previously well studied.

In status asthmaticus, muscle relaxant is frequently added to decrease fatal outcome while waiting for corticosteroid to take effect. Magnesium sulfate is the effective muscle relaxant commonly used in our hospital and worldwide to reduce asthma severity. $\mathrm{MgSO}_{4}$ can relax smooth muscle by two mechanisms. Firstly, it inhibits the interaction between calcium and myosin. Secondly, magnesium inhibits cholinergic neuromuscular transmission which induces muscle fiber excitability. Intravenous $\mathrm{MgSO}_{4}$ has been frequently used and studied in severe asthma than inhaled form. However, there is increasing evidence that inhaled $\mathrm{MgSO}_{4}$ may helpful in adult asthmatic exacerbations and in some cases of childhood asthmatic attacks. In children with severe asthma exacerbation, inhaled $\mathrm{MgSO}_{4}$ should be used early in order to get a good outcome. ${ }^{7}$ As mention in GINA 2015, the efficacy of nebulized $\mathrm{MgSO}_{4}$ is not clear but it can be used in a mixed form with salbutamol instead of normal saline to provides greater benefit. However, there was a study reported nebulized $\mathrm{MgSO}_{4}$ in moderate asthma exacerbation as an adjuvant treatment showed no benefit to standard treatment. ${ }^{8}$ There is a lack of evidence to summarize the benefit of nebulized $\mathrm{MgSO}_{4}$ children with acute asthmatic attack. Therefore, this study compared efficacy and safety of nebulized $\mathrm{MgSO}_{4}$ and nebulized ipratropium bromide with fenoterol in our childhood population who present with moderate to severe asthmatic attacks.

\section{Material and Methods Patients}

The double blind, randomized, controlled pilot study was performed at Queen Sirikit National Institute of Child Health, Bangkok, Thailand, from December $1^{\text {st }}, 2015$ to January $31^{\text {st }}$, 2017. The inclusion criteria were children, aged 2-15 years, with moderate to severe asthma exacerbation who failed to improve after the treatment with three doses of nebulized salbutamol (patients who had PRAM score $\geq 4$ defined by study of Ducharme FM et al) ${ }^{8}$ were enrolled into our study. The patients with following conditions 1) had history of bronchopulmonary dysplasia, immune deficiency, cystic fibrosis, primary ciliary dyskinesia, vascular ring, foreign body aspiration, chronic lung disease, chronic heart disease 2) had contraindication to use $\mathrm{MgSO}_{4}$ because of hepatic or renal disease 3) allergic to $\mathrm{MgSO}_{4}$ or ipratropium bromide or fenoterol 4) had life threatening features 5) refused to give informed consent by themselves or their parents, were excluded from this study. All participants agreed to be involved in our study and provided written informed consent which approved by the institutional ethics committee.

\section{Study Protocol}

Thirty-three children with moderate to severe asthma exacerbation were enrolled in our study and written informed consents were obtained from their parents. The baseline characteristic data included age, sex, body weight, height, race, duration of symptom, history of pneumonia, birth delivery, feeding history, personal history of atopy, parental history of atopy, parental smoking, history of nursery attendance, pets, skin prick test of aeroallergen and current medication of atopic disease (asthma, allergic rhinitis, allergic conjunctivitis and atopic dermatitis) were recorded.

All 33 patients were randomized into two groups by a computer-generate random sequence. The first group received three doses of $2.5 \mathrm{ml}$ of isotonic $\mathrm{MgSO}_{4}$ nebulizer (6\% solution) mixed with NSS up to $4 \mathrm{ml}, 30$ minutes apart. In the second group, the patients with body weight less than $20 \mathrm{~kg}$ received three doses of inhaled ipratropium bromide/fenoterol $0.5 \mathrm{ml}$ (ipratropium bromide $250 \mathrm{mcg}$, fenoterol $125 \mathrm{mcg}$ ) mixed with normal saline up to $4 \mathrm{ml}, 30$ minutes apart. The patients with body weight $>20 \mathrm{~kg}$ received ipratropium bromide/fenoterol $1 \mathrm{ml}$ (ipratropium bromide $0.5 \mathrm{mg}$, fenoterol $250 \mathrm{mcg}$ ). Each nebulize solution was prepared by the nurse who did not get involve in our research. All patients were evaluated for PRAM score, respiratory rate, heart rate, blood pressure, oxygen saturation, adverse reaction (flushing, hypotension, tremor, reflex, paralysis) at baseline and after each nebulizer at 30 minutes, 60 minutes, 90 minutes, 120 minutes, 240 minutes, 24 hours and 48 hours. All children were initially treated with intravenous hydrocortisone $5 \mathrm{mg} / \mathrm{kg} /$ dose every 6 hour and oxygen supplement. The addition treatments by the ward attending were also recorded. The $\mathrm{MgSO}_{4}$ level was measured twice, at initial treatment and at 2 hours after the last dose of each nebulized treatment. The hospital length of stay was also recorded as the secondary outcome.

\section{Isotonic $\mathrm{MgSO}_{4}$ preparation}

Nebulize isotonic $\mathrm{MgSO}_{4}$ solution (6\% solution) was produced under the calculation of our institution's pharmacist. The $50 \% \mathrm{MgSO}_{4} 0.3 \mathrm{ml}(150 \mathrm{mg})$ was diluted in sterile water 2.2 $\mathrm{ml}$ to change the solution to $245 \mathrm{mmol} / \mathrm{L}(337 \mathrm{mosm} / \mathrm{L})$, the same osmolarity as in MAGNETIC study.

\section{Outcomes}

Our primary outcome was the change of PRAM score at 30 minutes, 60 minutes, 90 minutes, 120 minutes and $240 \mathrm{~min}$ utes post randomization. Secondary outcome were adverse event from nebulized $\mathrm{MgSO}_{4}$ or nebulized ipratropium bromide/fenoterol and length of stay in hospital.

\section{Statistical analysis}

The study is a pilot study of two childhood groups receiving different treatment for severe asthma exacerbation. Each group composed of 15-30 candidates. Data was recorded and analyzed by SPSS software version16. The descriptive analysis using means, standard deviations, medians, and range for quantitative variables, frequencies and percentages for qualitative variables. Independent $t$-test was mainly used for continuous variables and Fisher's exact test was used for categorical variables. Results were considering to be statistically significant at $\mathrm{p} \leq 0.05$. 


\section{Design of the study}

Nebulization: Isotonic $\mathrm{MgSO}_{4} 2.5 \mathrm{ml}+$ NSS $1.5 \mathrm{ml}$ ( 3 doses), 30 min each at ER (during wait for admission)/Ward

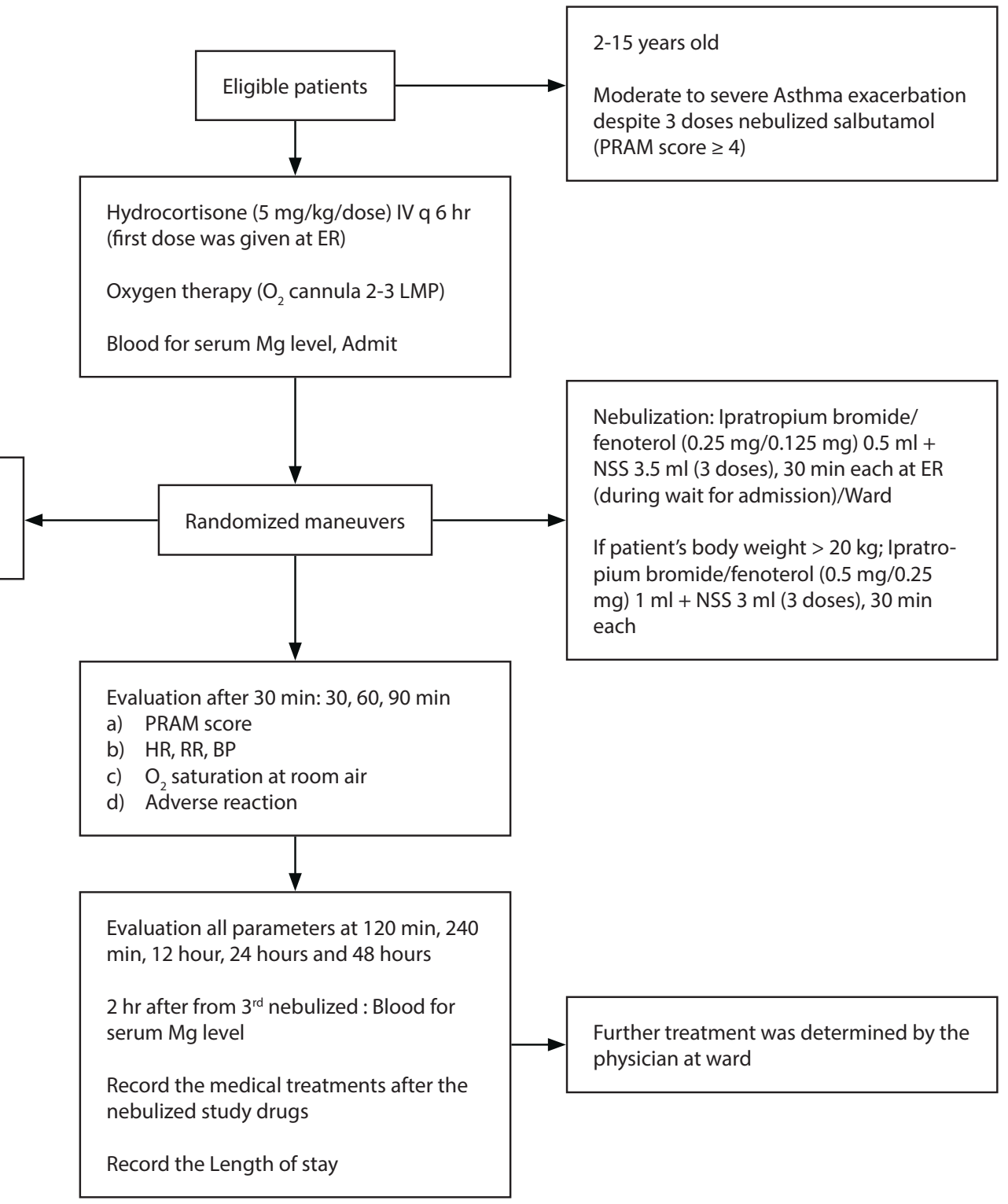

\section{Result}

Forty children with moderate to severe asthma exacerbation were included into our study but 7 were not eligible (Figure 1). Hence, thirty-three children with moderate to severe asthma were enrolled in to our study. All were Thai ethnic background. The standard therapy of acute asthmatic attack included three doses of nebulized salbutamol, systemic corticosteroid and oxygen were applied to all patients. Sixteen children were randomized to receive nebulized $\mathrm{MgSO}_{4}$ and seventeen children were randomized to receive nebulized ipratropium bromide/fenoterol.

The mean age of nebulized $\mathrm{MgSO}_{4}$ group was $4.18 \pm 1.77$ (age 2-11.2 years old) and nebulized ipratropium bromide/fenoterol was $5.41 \pm 2.83$ years (age ranged from 2.1-11.3 years old). Boy was predominantly in both groups $(62.5 \%$ and $64.7 \%$ for nebulized $\mathrm{MgSO}_{4}$ and nebulized ipratropium bromide/fenoterol, respectively) as shown in Table 1 . There were no statistically significant difference between the two study groups in baseline characteristics; mean age, body weight, height, allergic backgrounds, family history of asthma and baseline asthma severity score (PRAM score) besides the house dust mite sensitization, as shown in Table 1. There were 32 patients in moderate asthma (PRAM score 4-7) and only 1 patient in severe asthma (PRAM score 8); this child received inhaled ipratropium bromide/fenoterol. Allergic rhinitis was the most common comorbidity in both groups (56\% in nebulized $\mathrm{MgSO}_{4}$ and $47 \%$ in nebulized ipratropium bromide/fenoterol, respectively). The second comorbidity was cow's milk protein allergy ( 2 children in nebulized $\mathrm{MgSO}_{4}$ group and 2 children in nebulized ipratropium bromide/fenoterol group, respectively). Parental asthma in $\mathrm{MgSO}_{4}$ group (father $=18.75 \%$ and mother $=31.25 \%$ ) was higher than in nebulized ipratropium bromide/ fenoterol group (father $=11.7 \%$ and mother $=5.8 \%$ ). All patients had aeroallergen sensitization and house dust mite was found the most. However, house dust mite sensitization was found higher in ipratropium bromide/fenoterol group than in $\mathrm{MgSO}_{4}(\mathrm{p}=0.039)$ group. The skin test were sensitized to cockroach, cat dander, dog epithelium, Bermuda grass, Johnson grass and mold. For the environmental exposure, the most 


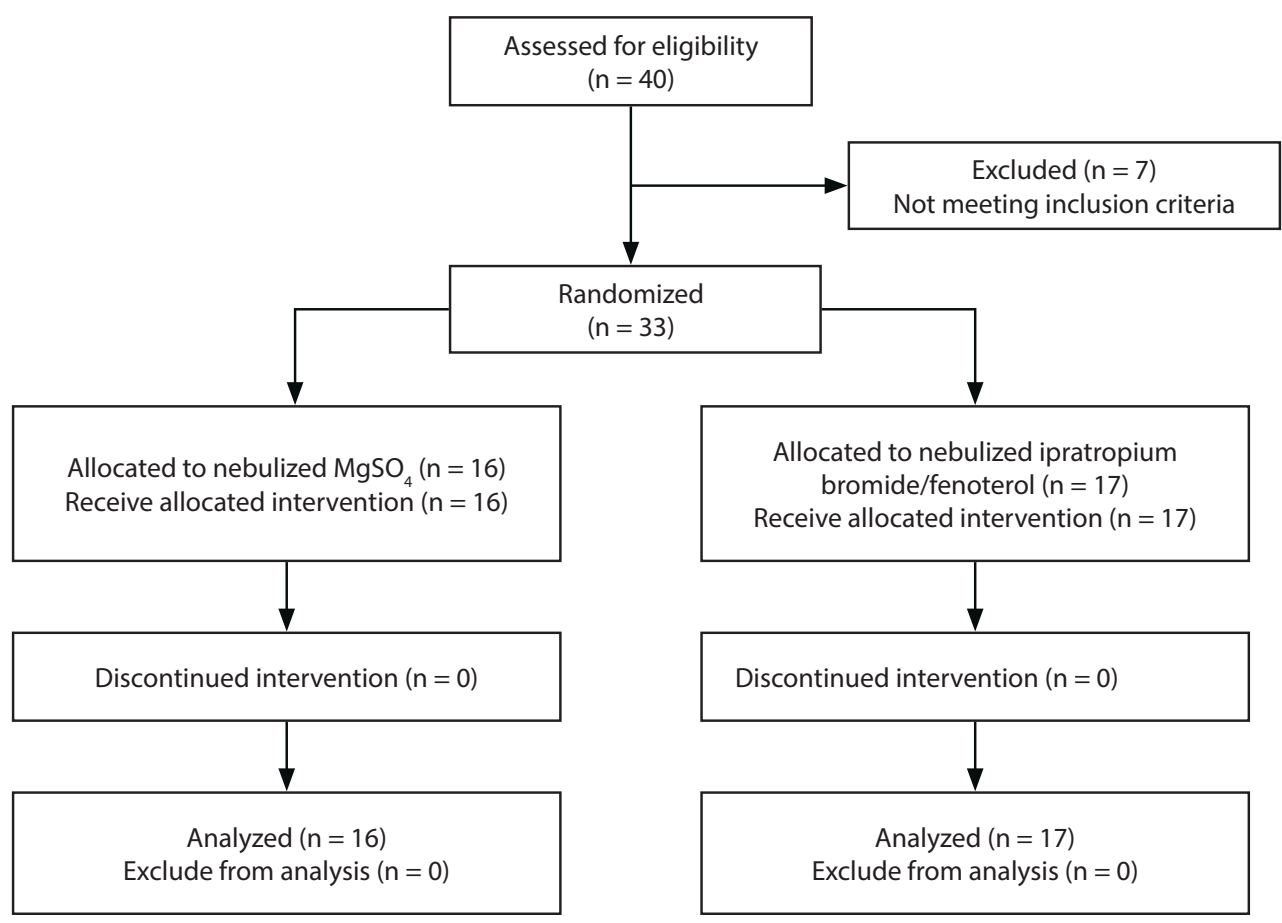

Figure 1. Flow diagram of the study

Table 1. Comparison of the baseline characteristics between the two groups of participants.

\begin{tabular}{|c|c|c|c|}
\hline Baseline characteristics & $\begin{array}{c}\mathrm{MgSO}_{4} \\
(\mathrm{~N}=16)\end{array}$ & $\begin{array}{c}\text { Ipratropium } \\
\text { bromide/fenoterol } \\
(\mathrm{N}=17)\end{array}$ & P-value \\
\hline Age (year), & $4.18 \pm 1.77$ & $5.41 \pm 2.83$ & 0.140 \\
\hline Male & $10(62.5)$ & $11(64.7)$ & 1.000 \\
\hline Body weight (kg) & $17.77 \pm 4.05$ & $21.44 \pm 8.32$ & 0.371 \\
\hline Height $(\mathrm{cm})$ & $103.4 \pm 11.24$ & $110.71 \pm 15.29$ & 0.195 \\
\hline \multicolumn{4}{|l|}{ Duration of symptom } \\
\hline$<6 \mathrm{~h}$ & $1(6.2)$ & $4(23.5)$ & 0.335 \\
\hline$\geq 6 \mathrm{~h}$ & $15(93.7)$ & $13(76.4)$ & 0.335 \\
\hline Only Breastfeeding & $2(12.5)$ & $7(41.1)$ & 0.118 \\
\hline \multicolumn{4}{|l|}{ Allergy history } \\
\hline Allergic rhinitis & $9(56)$ & $8(47)$ & 0.732 \\
\hline Food allergy & $2(12.5)$ & $2(11.7)$ & 1.000 \\
\hline Allergic conjunctivitis & $1(6.2)$ & $2(11.7)$ & 1.000 \\
\hline \multicolumn{4}{|l|}{ Aeroallergen sensitization } \\
\hline House dust mite & $10(62.5)$ & $16(94.1)$ & 0.039 \\
\hline American Cockroach & $4(25)$ & $12(75)$ & 0.708 \\
\hline Cat dander & $5(31.2)$ & $3(17.6)$ & 0.678 \\
\hline Dog epithelium & $3(18.7)$ & $4(23.5)$ & 1.000 \\
\hline Mold & $3(18.7)$ & $3(17.6)$ & 1.000 \\
\hline Bermuda grass & $4(25)$ & $3(17.6)$ & 0.688 \\
\hline Johnson grass & $2(12.5)$ & 0 & 0.227 \\
\hline
\end{tabular}

Data are mean (SD; range), or $\mathrm{n}(\%)$ 
Table 1. (Continued)

\begin{tabular}{|c|c|c|c|}
\hline Baseline characteristics & $\begin{array}{c}\mathrm{MgSO}_{4} \\
(\mathrm{~N}=16)\end{array}$ & $\begin{array}{c}\text { Ipratropium } \\
\text { bromide/fenoterol } \\
(\mathbf{N}=17)\end{array}$ & P-value \\
\hline \multicolumn{4}{|l|}{ Family history of atopy } \\
\hline Asthma, Father/Mother & $3(18.7) / 5(31.2)$ & $2(11.7) / 1(5.8)$ & $0.656 / 0.085$ \\
\hline Allergic rhinitis, Father/Mother & $1(6.25) / 3(18.7)$ & $3(17.6) / 3(17.6)$ & $0.601 / 1.000$ \\
\hline Baseline PRAM score & $5.25 \pm 1.06$ & $5.12 \pm 1.26$ & 0.748 \\
\hline Pretreatment Mg level & $2.15 \pm 0.22$ & $2.16 \pm 0.15$ & 0.840 \\
\hline Heart rate (per min) & $157.31 \pm 19.1$ & $132 \pm 36.85$ & 0.006 \\
\hline Respiratory rate (per min) & $41.75 \pm 10.68$ & $38.9 \pm 10.53$ & 0.604 \\
\hline Systolic blood pressure (mmHg) & $110.5 \pm 8.03$ & $111.05 \pm 10.82$ & 0.775 \\
\hline Diastolic blood pressure (mmHg) & $62.68 \pm 6.82$ & $61 \pm 9.5$ & 0.166 \\
\hline Pulse oximetry (\%) & $95.5 \pm 1.78$ & $96.05 \pm 2.74$ & 0.497 \\
\hline \multicolumn{4}{|l|}{ Medication of post-treatment nebulized study } \\
\hline ventolin & $16.25 \pm 8.33$ & $16.11 \pm 8.45$ & 0.964 \\
\hline ipratropium bromide/fenoterol & $5.81 \pm 5.25$ & $6.41 \pm 5.42$ & 0.750 \\
\hline continuous nebulization of salbutamol & $1.68 \pm 0.47$ & $1.76 \pm 0.43$ & 0.632 \\
\hline intravenous $\mathrm{MgSO}_{4}$ & $1.68 \pm 0.47$ & $1.94 \pm 0.24$ & 0.070 \\
\hline methylprednisolone & $1.75 \pm 0.44$ & $1.88 \pm 0.33$ & 0.340 \\
\hline subcutaneous terbutaline & $1.75 \pm 0.44$ & $1.94 \pm 0.24$ & 0.144 \\
\hline
\end{tabular}

Data are mean (SD; range), or $\mathrm{n}(\%)$

common was cigarette smoking (75\% in nebulized $\mathrm{MgSO}_{4}$, $76.4 \%$ in nebulized ipratropium bromide/fenoterol). Patients in both groups mainly had acute asthma symptoms more than 6 hours. There was no statistically significant difference between two groups in the onset, duration of disease and medical treatment.

We found the baseline heart rate in $\mathrm{MgSO}_{4}$ group was significantly higher than in ipratropium bromide/fenoterol group $(\mathrm{p}=0.006)$. There were no statistically significant difference between two groups in baseline respiratory rates $(p=0.604)$, systolic blood pressure $(\mathrm{p}=0.775)$, diastolic blood pressure $(\mathrm{p}=$ $0.166)$, oxygen saturation $(\mathrm{p}=0.497)$, PRAM score $(\mathrm{p}=0.748)$, pretreatment $\mathrm{Mg}$ level $(\mathrm{p}=0.840)$ and medication of post treatment nebulized study as shown in Table 2 .

The primary outcome, the change of PRAM score at $30 \mathrm{~min}$ utes, 60 minutes and 90 minutes after each nebulized $\mathrm{MgSO}_{4}$ and nebulized ipratropium bromide/fenoterol and at $120 \mathrm{~min}-$ utes, 240 minutes, 12 hours, 24 hours and 48 hours from initial baseline evaluation was shown in Table 3 and Figure 2. Interestingly, all patients in both groups had clinical improvement at 60 minutes after the second dose nebulized treatment. However, there was no statistically significant difference between two groups in PRAM score assessment. In addition to PRAM score, we also evaluated patient's respiratory rate and found that the mean respiratory rate at 12 hours was significantly higher in $\mathrm{MgSO}_{4}$ group (35.9/min) than in ipratropium bromide group (31.2/min) (Table 3).
Table 2. Comparison of mean PRAM score in nebulized $\mathrm{MgSO}_{4}$ and nebulized ipratropium bromide/fenoterol group.

\begin{tabular}{|lccc|}
\hline Time & $\begin{array}{c}\mathbf{M g S O}_{4} \\
(\mathbf{N}=\mathbf{1 6}) \\
(\mathrm{Mean} \pm \mathbf{S D})\end{array}$ & $\begin{array}{c}\text { Ipratropium } \\
\text { bromide/fenoterol } \\
(\mathbf{N}=\mathbf{1 7}) \\
(\mathbf{M e a n} \pm \mathbf{S D})\end{array}$ & P-value \\
\hline Baseline & $5.25 \pm 1.06$ & $5.12 \pm 1.26$ & 0.748 \\
\hline 30 minutes & $4.19 \pm 1.6$ & $3.71 \pm 1.21$ & 0.336 \\
\hline 60 minutes & $3.62 \pm 1.82$ & $3 \pm 1.65$ & 0.310 \\
\hline 90 minutes & $3.75 \pm 1.94$ & $2.94 \pm 1.47$ & 0.187 \\
\hline 120 minutes & $3.38 \pm 2.27$ & $2.82 \pm 1.46$ & 0.412 \\
\hline 240 minutes & $2.94 \pm 1.84$ & $2.24 \pm 1.71$ & 0.266 \\
\hline 12 hours & $2.44 \pm 1.54$ & $3 \pm 1.62$ & 0.316 \\
\hline 24 hours & $2.06 \pm 1.8$ & $1.71 \pm 1.75$ & 0.570 \\
\hline 48 hours & $1.38 \pm 1.4$ & $1.29 \pm 1.7$ & 0.884 \\
\hline
\end{tabular}

We also monitored heart rate, blood pressure, pulse oximetry at 30 minutes, 60 minutes, 90 minutes, 120 minutes, 240 minutes, 12 hours, 24 hours and 48 hours after treatment and the details was shown in Table 3. The mean heart rate at 24 hours was higher in nebulized $\mathrm{MgSO}_{4}$ group than in 
Table 3. Comparison of the characteristics of the participants in the nebulized $\mathrm{MgSO}_{4}$ and nebulized ipratropium bromide/ fenoterol groups during study

\begin{tabular}{|c|c|c|c|}
\hline Parameters & $\begin{array}{c}\mathrm{MgSO}_{4} \\
(\mathrm{~N}=16) \\
(\mathrm{Mean} \pm \mathrm{SD})\end{array}$ & $\begin{array}{c}\text { Ipratropium } \\
\text { bromide/fenoterol } \\
(\mathbf{N}=17) \\
(\text { Mean } \pm \text { SD })\end{array}$ & p value \\
\hline \multicolumn{4}{|l|}{ Heart rate (beats per min) } \\
\hline 30 minutes & $145.75 \pm 12.12$ & $45 \pm 16.74$ & 0.884 \\
\hline 60 minutes & $138.93 \pm 14.13$ & $144.29 \pm 17.07$ & 0.350 \\
\hline 90 minutes & $138.62 \pm 14.17$ & $141.05 \pm 15.16$ & 0.638 \\
\hline 120 minutes & $137.25 \pm 18.79$ & $138.11 \pm 18.77$ & 0.895 \\
\hline 240 minutes & $140.75 \pm 16.51$ & $131.82 \pm 15.37$ & 0.118 \\
\hline 12 hours & $128.93 \pm 16.68$ & $119.7 \pm 15.63$ & 0.111 \\
\hline 24 hours & $138 \pm 14.24$ & $125 \pm 17.3$ & 0.025 \\
\hline 48 hours & $127.13 \pm 19.01$ & $108.17 \pm 12.5$ & 0.002 \\
\hline \multicolumn{4}{|l|}{ Respiratory rate (breaths per min) } \\
\hline 30 minutes & $38.25 \pm 8.25$ & $34.17 \pm 7.21$ & 0.141 \\
\hline 60 minutes & $35.56 \pm 7.77$ & $37 \pm 13.21$ & 0.708 \\
\hline 90 minutes & $35.93 \pm 6.8$ & $34.8 \pm 10.14$ & 0.715 \\
\hline 120 minutes & $34.68 \pm 5.85$ & $34.11 \pm 9.76$ & 0.792 \\
\hline 240 minutes & $34 \pm 6.28$ & $33.35 \pm 9.66$ & 0.790 \\
\hline 12 hours & $35.93 \pm 4.63$ & $31.23 \pm 7.22$ & 0.035 \\
\hline 24 hours & $31.87 \pm 5.86$ & $31.17 \pm 6.93$ & 0.739 \\
\hline 48 hours & $32.4 \pm 5.02$ & $28.7 \pm 4.74$ & 0.082 \\
\hline Systolic blood pressure $90 \mathrm{~min}(\mathrm{mmHg})$ & $105.06 \pm 10.59$ & $110.29 \pm 12.1$ & 0.053 \\
\hline Diastolic blood pressure $90 \mathrm{~min}(\mathrm{mmHg})$ & $56.68 \pm 10.91$ & $58.35 \pm 8.16$ & 0.673 \\
\hline \multicolumn{4}{|l|}{ Pulse oximetry (\%) } \\
\hline 30 minutes & $96.62 \pm 21.56$ & $96.94 \pm 2.43$ & 0.696 \\
\hline 60 minutes & $96.65 \pm 2 . .14$ & $96.58 \pm 1.73$ & 0.982 \\
\hline 90 minutes & $96.06 \pm 2.32$ & $96.64 \pm 2.31$ & 0.475 \\
\hline 120 minutes & $95.68 \pm 2.65$ & $96.82 \pm 2.42$ & 0.209 \\
\hline 240 minutes & $96.62 \pm 2.21$ & $97.64 \pm 1.8$ & 0.155 \\
\hline 12 hours & $96.62 \pm 2.30$ & $96.7 \pm 2.2$ & 0.963 \\
\hline 24 hours & $97.06 \pm 2.08$ & $97.29 \pm 1.72$ & 0.729 \\
\hline 48 hours & $97.86 \pm 1.95$ & $97 \pm 2.66$ & 0.412 \\
\hline Post treatment Mg level (mg/dL) & $2.29 \pm 0.19$ & $2.20 \pm 0.18$ & 0.184 \\
\hline
\end{tabular}




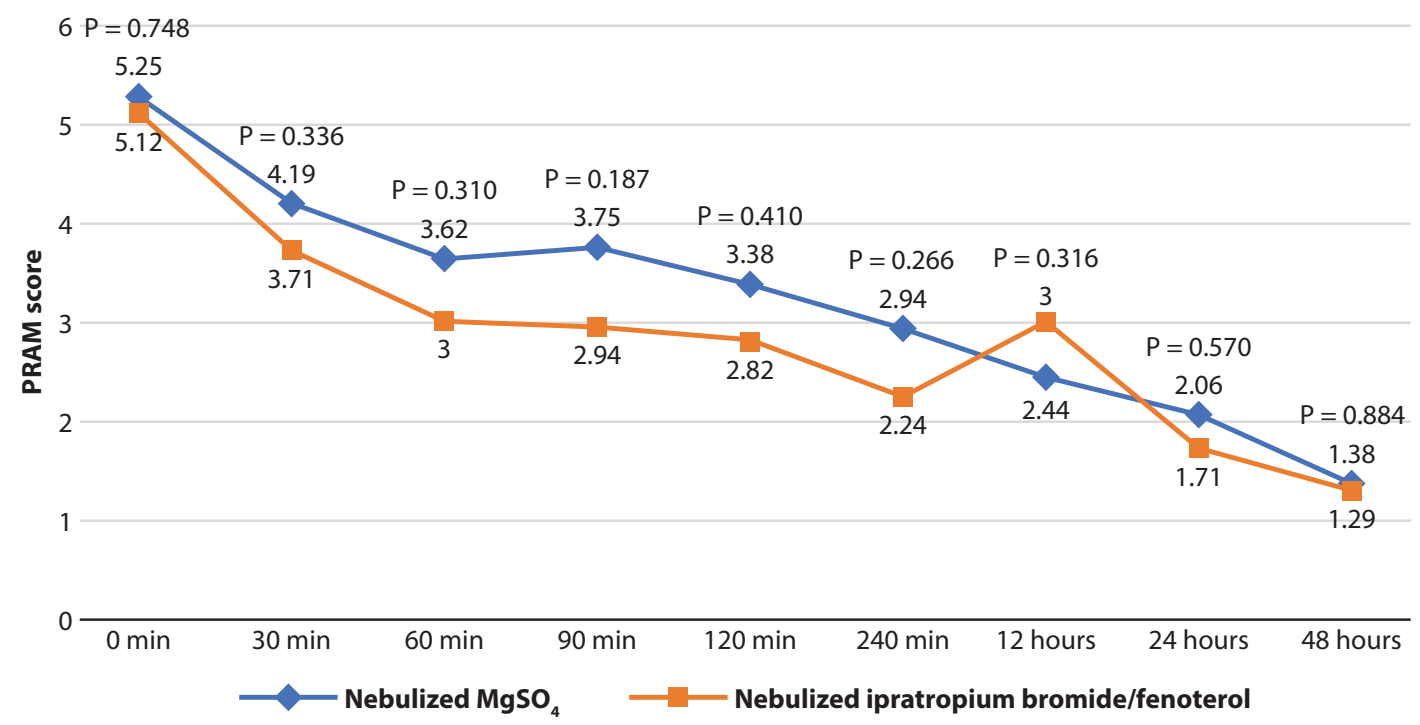

Figure 2. Comparison of PRAM scores overtime between nebulized $\mathrm{MgSO}_{4}$ and nebulized ipratropium bromide/fenoterol groups.

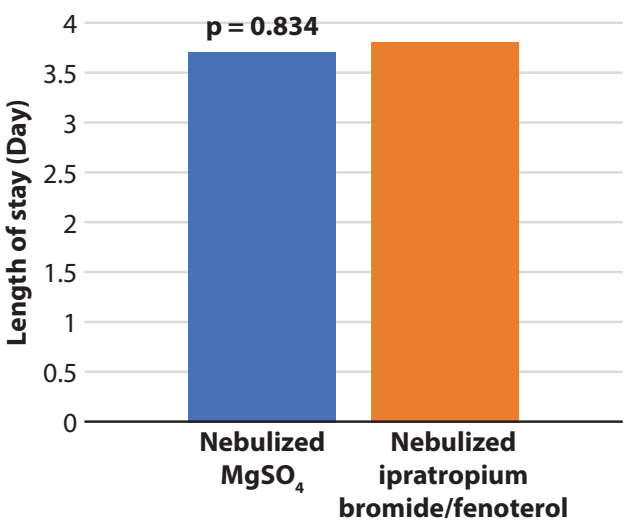

Figure 3. Comparative of hospital length of stay between nebulized $\mathrm{MgSO}_{4}$ and nebulized ipratropium bromide/fenoterol groups.

ipratropium bromide/fenoterol group (138/min versus 125/ $\min )(\mathrm{p}=0.025)$. These higher heart rates were also seen at 48 hours $(127.13 / \mathrm{min}$ versus $108.17 / \mathrm{min})(\mathrm{p}=0.002)$.

The secondary outcome, the adverse event found during nebulized treatment was nasal sting sensation. Two patients in nebulized $\mathrm{MgSO}_{4}$ group reported nasal sting sensation during the first dose of treatment but the symptom went after finishing that dose. One of whom having nasal sting sensation also had mild vomiting after the third dose of $\mathrm{MgSO}_{4}$. There was no other adverse event including flush, hypotension, hyporeflexia or paralysis.

The magnesium levels were measured twice at the baseline and at 2 hours after finishing nebulization. The mean pre-treatment, serum magnesium levels in $\mathrm{MgSO}_{4}$ group and in ipratropium bromide/fenoterol group were $2.15 \mathrm{mg} / \mathrm{dL}$ and 2.16 $\mathrm{mg} / \mathrm{dL}$, respectively. The mean serum magnesium levels of post-treatment in $\mathrm{MgSO}_{4}$ group and in ipratropium bromide/ fenoterol group were $2.20 \mathrm{mg} / \mathrm{dL}$ and $2.29 \mathrm{mg} / \mathrm{dL}$, respectively. There was no statistically significant difference between two groups ( $\mathrm{p}=0.184)$, as shown in Table 3 .
The hospital length of stay was shown in Figure 3. The mean length of stay was also similar between two groups; $3.76 \pm 1.1$ days in nebulized $\mathrm{MgSO}_{4}$ group versus $3.86 \pm 1.5$ days in nebulized ipratropium bromide/fenoterol group $(\mathrm{p}=0.834)$.

As we know, the most effective reliever in early asthmatic attack is beta ${ }_{2}$ agonist. However, this treatment is not sufficient in severe cases. The necessary additive anti-inflammation, such as systemic corticosteroid needs 4-6 hours to improve asthma outcome. Therefore, ipratropium bromide, the anticholinergic, is suggested by GINA and Thai guideline to use after failure in treatment by salbutamol. However, there is no unmixed nebulized ipratropium bromide available in Thailand. In our country, we need to use either ipratropium bromide/fenoterol or ipratropium bromide/salbutamol to treat patients with acute severe asthmatic attack. Ipratropium bromide/fenoterol is easier to obtain and cheaper than ipratropium bromide/salbutamol. However, there was only one child study which demonstrated efficacy of ipratropium bromide in Thailand. ${ }^{9}$ We confirmed that nebulized ipratropium bromide/fenoterol is effective and safe. In our study, nebulized ipratropium bromide/fenoterol decreased the severity of acute asthma as early as 30 minutes after the treatment. This similar effect was also seen in patients treated with to nebulized $\mathrm{MgSO}_{4}$ (Table 3). The results showed no significantly difference in PRAM score at 30 minutes, 60 minutes, 90 minutes, 120 minutes and 240 minutes. This outcome was similar to the randomized trial of nebulized magnesium in moderate and severe acute asthmatic children by Alansari. ${ }^{11}$ Nonetheless, in Alansari's study, they used mixed nebulized $\mathrm{MgSO}_{4}$ and albuterol instead of isolated nebulized magnesium sulfate as we did.

The systematic review of meta-analysis showed good efficacy of $\mathrm{MgSO}_{4}$ treatment in adult asthma both intravenous and nebulized. However, in some previous studies, children with acute asthmatic attack were not well improved with nebulized $\mathrm{MgSO}_{4}$ compared to intravenous $\mathrm{MgSO}_{4}{ }^{6}$ This was argued by the MAGNETIC study which suggested that children with acute asthma would respond to nebulized $\mathrm{MgSO}_{4}$ if we could treat 
patients early, as within 6 hours of onset of acute asthma. ${ }^{7}$ The benefit of inhaled $\mathrm{MgSO}_{4}$ was also confirmed by our previous study which performed in Thai children with severe asthma. ${ }^{12}$ In that study, the nebulized $\mathrm{MgSO}_{4}$ was as effective as intravenous $\mathrm{MgSO}_{4}$ to control severe acute asthma. In this study, we confirmed the efficacy of nebulized $\mathrm{MgSO}_{4}$ which can reduce the severity of acute asthma since the first hour of treatment (Table 3). However, we could not conclude the sustainability effect of nebulized $\mathrm{MgSO}_{4}$ at 12 hours, 24 hours and 48 hours after treatment because of the short duration of the medicine. ${ }^{13}$ By this reason, therefore, we could not confirmed whether both medication decrease hospital length of stay because there was not statistically significant in hospital length of stay.

In safety part, there was no serious adverse reaction in both nebulized $\mathrm{MgSO}_{4}$ and nebulized ipratropium bromide/fenoterol. We found only two patients reported nasal sting sensation during the first dose of nebulized $\mathrm{MgSO}_{4}$ treatment. One patient who had nasal sting sensation also had mild vomiting. Their symptoms were spontaneous improved without the requirement of $\mathrm{MgSO}_{4}$ discontinuation or extra treatment. In addition, serum magnesium levels did not increase in both treatment groups. The safety of inhaled $\mathrm{MgSO}_{4}$ in our study was not differed from the two previous studies of Daengsuwan $\mathrm{T}$ and Mahajan. ${ }^{12,14}$ There was no side effect of nebulized ipratropium bromide/fenoterol in our study, similar to the study of Watson. ${ }^{15}$

This the first study to compare the efficacy and the safety of nebulized $\mathrm{MgSO}_{4}$ and nebulized ipratropium bromide/fenoterol. Our strength is the randomized double blind controlled trial. We also demonstrated the preparation of isotonic $\mathrm{MgSO}_{4}$ which was easy to apply. However, limitations of this study were the small sample size and most of our patients (32/33) had moderate asthmatic attack, measured by PRAM score. In addition, the most of our patients presented to our hospital later than 6 hours of onset of asthmatic attack.

\section{Conclusion}

This double blind, randomized, controlled study demonstrated non-inferior efficacy of nebulized $\mathrm{MgSO}_{4}$ and nebulized ipratropium bromide/fenoterol among Thai children with moderate asthma exacerbation. There was no serious adverse reaction in both treatments.

\section{Acknowledgments}

This study was financially supported by Queen Sirikit National Institute of Child Health, Bangkok, Thailand.

\section{References}

1. Global Initiative for Asthma Executive Committee. Global Strategy for Asthma Diagnosis and Prevention. Updated 2015 [Internet]. Bethesda: Global Initiative for Asthma; 2015 [cited 2015 Nov 10]. Available from: http://ginasthma.org/2015-gina-report-global-strategy-for-asthma-manag ement-and-prevention/.

2. National Asthma Education and Prevention Program. Expert panel report 3: guidelines for the diagnosis and management of asthma Full report 2007[Internet]. [Place unknown]: U.S. Department of Health and Human Services, National Institute of Health, National Heart, Lung, and Blood Institute; c2007 [cited 2016 Feb 7]. Available from: http://www.nhlbi.nih. gov/guidelines/asthma/asthgdln.htm.

3. Rodrigo GJ, Castro-Rodriguez JA. Anticholinergics in the treatment of children and adults with acute asthma: systematic review with meta -analysis. Thorax. 2005;60(9):740-6.

4. Griffiths B, Ducharme FM. Combined inhaled anticholinergics and short -acting beta2-agonists for initial treatment of acute asthma in children. Paediatr Respir Rev. 2013;14:234-5.

5. Kelly HW. Magnesium sulfate for severe acute asthma in children. J Pediatr Pharmacol Ther. 2003;8:40-5.

6. Shan Z, Rong Y, Yang W, Wang D, Yao P, Xie J, et al. Intravenous and nebulized magnesium sulfate for treating acute asthma in adults and children: a systematic review and meta-analysis. Respir Med. 2013;107: 321-30.

7. Powell CV, Kolamunnage -Dona R, Lowe J, Boland A, Petrou S, Doull I,et al. Magnesium sulphate in Acute Severe Asthma in Children (MAGNETIC) a randomised placebo controlled trial. Lancet Respir Med. 2013;11:301-8.

8. Turker S, Dogru M, Yildiz F, Yilmaz SB. The effect of nebulised magnesium sulphate in the management of childhood moderate asthma exacerbations as adjuvant treatment. Allergol Immunopathol (Madr). 2017; 45(2):115- 20.

9. Ducharme FM, Chalut D, Plotnick L, Saudie C, Kudirka D, Zhang X, et al. The Pediatric Respiratory Assessment Measure: a valid clinical score for assessing acute asthma severity from toddlers to teenagers. J Pediatr. 2008;152:476-80.

10. Wattanasomsin A, Phipatanakul W. Comparison of nebulized ipratropium bromide with salbutamol vs. salbutamol alone in acute exacerbation in children. Ann. Allergy Asthma Immunol. 2006;96(5):701-6.

11. Alansari K, Ahmed W, Davidson BL, Alamri M, Zakaria I, Alrifaai M. Nebulized magnesium for moderate and severe pediatric asthma: A randomized trial. Pediatr Pulmonol. 2015 ;50(12):1191-9.

12. Daengsuwan T, Watanatham S. A comparative pilot study of the efficacy and safety of nebulized magnesium sulfate and intravenous magnesium sulfate in children with severe acute asthma. Asian Pac J Allergy Immunol. 2017; 35(2):108-12.

13. Noppen N, Vanmalele L, Impens N, Schandevyl W. Bronchodilating effect of intravenous magnesium sulfate in acute bronchial asthma. Chest. 1990;97:373-6.

14. Mahajan P, Haritos D, Rosenberg N, Thomas R. Comparison of nebulized magnesium sulfate plus salbutamol plus saline in children with exacerbations of mild to moderate asthma. J Emerg Med. 2004; 27:21-5.

15. Watson W, Becker A, Simons F. Comparison of ipratropium solution, fenoterol solution, and their combination administered by nebulizer and face mask to children with acute asthma. J Allergy Clin Immunol. 1988; 82:1012-8. 